\title{
Leitura e formação do leitor: olhares sobre a prática docente
}

Reading and competent reader education:

\author{
views on teaching practice \\ Lectura y capacitación de lectores: \\ puntos de vista sobre la práctica docente
}

\author{
Olívia Coelho da Silva \\ Rede municipal de Fortaleza, Fortaleza/CE - Brasil \\ Universidade Federal do Ceará, Fortaleza/CE - Brasil \\ Silvana Mendes Sabino Soares \\ Rede municipal de Fortaleza, Fortaleza/CE - Brasil \\ Universidade Federal do Ceará, Fortaleza/CE - Brasil \\ Ana Paula de Medeiros Ribeiro \\ Universidade Federal do Ceará, Fortaleza/CE - Brasil
}

\section{Resumo}

Neste artigo, investigamos como professoras alfabetizadoras escolhem as leituras que oferecem às crianças no cotidiano das salas de aula. Trata-se de fragmentos de pesquisas realizadas em duas escolas públicas de Fortaleza Ceará. No estudo, de abordagem qualitativa do tipo descritiva, utilizamos as técnicas de entrevista semiestruturada e observação (LAKATOS; MARCONI, 2009; TRIVIÑOS, 1987). Os dados foram tratados por meio da Análise de Conteúdo (BARDIN, 2011), reforçada com triangulação entre as técnicas (MINAYO; ASSIS; SOUZA, 2005). Solé (1998), Soares (1998), Koch e Elias (2013), entre outros, sustentaram teoricamente as análises realizadas. Concluímos que as professoras consideravam o interesse dos alunos, a necessidade de contemplar a realidade e a aproximação ao cotidiano, buscando a diversidade de gêneros e a adequação ao nível de compreensão.

Palavras-chave: Alfabetização, Leitura, Formação leitora, Prática docente

\section{Abstract}

In this article, we investigate how literacy teachers choose the readings they offer to children in classroom. These are fragments of research carried out in two public schools in Fortaleza - Ceará. In this study, with a descriptive qualitative approach, we used the techniques of semi-structured interview and observation (LAKATOS; MARCONI, 2009; TRIVIÑOS, 1987). The data were treated through Content Analysis (BARDIN, 2011), reinforced with triangulation between the techniques (MINAYO; ASSIS; SOUZA, 2005). Solé (1998), Soares (1998), Koch and Elias (2013), among others, theoretically supported the analyzes performed. We concluded that the teachers considered the students' interest, the need to contemplate the reality and the approach to daily life, seeking diversity of genders and adapting to the level of understanding.

Keywords: Literacy, Reading, Reader training, Teaching practice

\section{Resumen}

En este artículo, investigamos cómo maestros de alfabetización eligen las lecturas que ofrecen a los niños en el aula. Estos son fragmentos de

Revista Educação Online, Rio de Janeiro, n. 37, mai-ago 2021, p. 55-72 
investigaciones llevadas a cabo en dos escuelas públicas de Fortaleza-Ceará. En el estudio, con un enfoque cualitativo de tipo descriptivo, utilizamos las técnicas de entrevista semiestructurada y observación (LAKATOS; MARCONI, 2009; TRIVIÑOS, 1987). Los datos fueron tratados a través del Análisis de Contenido (BARDIN, 2011), reforzado con triangulación entre las técnicas (MINAYO; ASSIS; SOUZA, 2005). Solé, (1998), Soares (1998), Koch y Elias (2013), entre otros, respaldaron teóricamente los análisis realizados. Llegamos a la conclusión de que los maestros consideraban el interés de los estudiantes, la necesidad de contemplar la realidad y el enfoque de la vida diaria, buscando la diversidad de géneros y la adaptación al nivel de comprensión.

Palabras clave: Alfabetización, Lectura, Formación de lectores, Práctica docente

\section{Das intenções deste escrito}

Em sociedades de cultura escrita, a leitura é uma habilidade básica de acesso ao patrimônio gráfico historicamente construído. É também importante meio de aprendizagens essenciais para prosseguimento na escola; por conseguinte, o domínio dessa habilidade é relevante na vida escolar e social.

O início se dá ainda na infância, em interações com famílias e comunidades, por meio de material escrito e de atos de leitura, bem como em instituições educativas, a partir da inserção das crianças em contextos letrados repletos de suportes e gêneros textuais.

Nesse cenário, professores responsáveis por turmas de crianças no início da escolaridade têm o desafio de contribuir para a formação de leitores, com vistas a lhes despertar o desejo de aprender a ler, a fim de que, apropriando-se desse saber, possam ler para aprender, comunicar-se, buscar informações necessárias à vida prática, deleitar-se e usufruir de momentos de prazer, ou seja, possam ler com variados objetivos (SOLÉ, 1998), aqueles que Ihes forem mais adequados, de acordo com a situação.

Diante de alunos ávidos por descobrir os mistérios do mundo, docentes precisam de sensibilidade para perceber os textos que os interessam, a fim de os motivar para ler e, paulatinamente, oferecer-lhes opções de textos e suportes, objetivando a inserção no universo cultural escrito.

Esse universo é composto por distintos gêneros textuais, entendidos como textos encontrados em nossa vida diária, que apresentam padrões sociocomunicativos caraterísticos, definidos por composições funcionais, 
objetivos enunciativos e estilos concretamente realizados na integração de forças históricas, sociais, institucionais e técnicas (MARCUSCHI, 2008, p. 155).

Neste artigo, discorremos sobre o modo como professoras da educação infantil (Infantil V, turma de crianças com idades entre 5 e 6 anos) e dos anos iniciais do ensino fundamental ( $1^{\circ}$ ao $3^{\circ}$ ano, turmas de crianças com idades entre 6 e 9 anos) escolhem as leituras que oferecem às crianças no cotidiano das salas de aula. Trata-se de recortes decorrentes de pesquisas de mestrado ${ }^{1}$ realizadas em duas escolas municipais de Fortaleza, capital do Ceará.

As pesquisas investigaram a prática pedagógica com a leitura na alfabetização, processo de apropriação da língua escrita, que envolve o desenvolvimento das habilidades de ler e escrever, o letramento, a competência leitora e a formação do leitor iniciante.

Os estudos foram motivados pelas questões centrais: Como são as práticas dos professores no trabalho pedagógico com a leitura na educação infantil e no ensino fundamental? O que fazem e como fazem para o desenvolvimento da competência leitora das crianças?

O ponto de interseção entre os estudos investigativos de natureza qualitativa foi uma das categorias, aqui denominada "seleção das leituras oferecidas no cotidiano da sala de aula"2, emersa a partir da realização de entrevistas semiestruturadas com professoras, sujeitos colaboradores da investigação, que, por meio da análise de suas práticas docentes, ajudaramnos a elucidar inquietações oriundas de nossas trajetórias profissionais com 0 objeto de estudo leitura.

\footnotetext{
1 SILVA, Olívia Coelho da. Formação do leitor: desafio à prática docente e à avaliação da aprendizagem. 2016. 200 f. Dissertação (Mestrado em Educação) - Universidade Federal do Ceará, Faculdade de Educação, Programa de Pós-graduação em Educação, Fortaleza, 2016. Disponível em: <http://www.repositorio.ufc.br/handle/riufc/16424>. Acesso em: 12 abr. 2020. Pesquisa devidamente aprovada pelo Comitê de Ética em Pesquisa (CEP) da Universidade Federal do Ceará (UFC), sob o parecer consubstanciado de ํㅜ 1.332 .785 .

SOARES, Silvana Mendes Sabino. O trabalho pedagógico com a leitura na educação infantil e no ensino fundamental: investigações sobre ensino e avaliação. 2017. 286 f. Dissertação (Mestrado em Educação) - Universidade Federal do Ceará, Faculdade de Educação, Programa de Pós-graduação em Educação, Fortaleza, 2017. Disponível em: <http://www.repositorio.ufc.br/handle/riufc/22506>. Acesso em: 12 abr. 2020.

Pesquisa devidamente aprovada pelo CEP/UFC, sob o parecer consubstanciado de $\mathrm{n}^{-}$ 1.956 .884 .

2 Originalmente, as categorias são: escolha do livro para os alunos e escolha das leituras.
} 
Sabemos, por diversos estudos e pesquisas, que ainda há uma parcela substancial de crianças que chegam aos anos finais do ensino fundamental, sem a consolidação das habilidades de alfabetização, especialmente, as relacionadas à leitura, e, por esse motivo, vivenciam dificuldades para ler e compreender textos mais complexos. Portanto, acreditamos na importância da mediação e do incentivo de professores na formação do leitor.

Essa postura docente se faz necessária, pois pode garantir a inserção das crianças em situações significativas de interação com diferentes gêneros textuais, o que converge para o desenvolvimento da formação leitora.

A realização de atividades com o uso social da língua, isto é, as ações de letramento (SOARES, 1998), promovem a familiarização dos alunos com os textos circulantes na esfera social além da escola. Nesse sentido, concordamos com Ausubel, Novak e Hanesian (1980, p. 30), ao afirmarem que a aprendizagem significativa acontece quando

[...] a tarefa de aprendizagem implica em relacionar, de forma não arbitrária e substantiva uma nova informação a outras com as quais o aluno já esteve familiarizado, e quando o aluno adota uma estratégia correspondente para assim proceder. (AUSUBEL; NOVAK; HANESIAN, 1980, p. 30)

Sobre o assunto, Soares (1998, p. 47) afirma: "alfabetizar e letrar são duas ações distintas, mas não inseparáveis" e, reitera: "[...] o ideal seria alfabetizar letrando, ou seja: ensinar a ler e escrever no contexto das práticas sociais da leitura e escrita, de modo que o indivíduo se tornasse, ao mesmo tempo, alfabetizado e letrado".

Desse modo, evidenciamos a ação docente na seleção de bons textos a serem lidos, para e com as crianças, em fase de descoberta desse objeto tecnológico que é a escrita e, consequentemente, a leitura. Temos a convicção de que é pelas mãos e voz de professores, leitores proficientes, que muitas crianças se encantam, constroem o gosto para ler, tornam-se leitoras autônomas e multiplicadoras de ações favoráveis à leitura.

A concepção de leitura considerada em nossas pesquisas é a interacional da língua, referendada por Koch e Elias (2013), de que os leitores são sujeitos ativos e interagem dialogicamente com o autor por meio do texto. Dessa forma, o sentido do lido é construído na interação entre texto e sujeito 
que o lê e lança mão de saberes, de sua história e das relações que estabelece com o texto e o contexto da leitura.

Com as referidas autoras, concebemos a leitura como "[...] atividade interativa altamente complexa de produção de sentidos, que se realiza evidentemente com base nos elementos linguísticos presentes na superfície textual e na sua forma de organização" (KOCH; ELIAS, 2013, p. 11).

Para ler, necessitamos, simultaneamente, manejar com destreza as habilidades de decodificar e apontar ao texto nossos objetivos, ideias e experiências prévias; precisamos nos envolver em um processo de previsão e inferência contínua, apoiada na informação proporcionada pelo texto e na própria bagagem, e em um processo que permita encontrar evidência ou rejeitar as previsões e inferências antes mencionadas (SOLÉ, 1998, p. 23).

Solé (1998), Koch e Elias (2013) compartilham olhares convergentes sobre a leitura, asseverando que, no processo didático dessa competência, é necessário considerarmos os objetivos da leitura como elementos importantes, que não devem ser deixados à margem na tarefa de ensinar as crianças a ler e, essencialmente, a compreender aquilo que leem.

Nesse sentido, Solé (1998) afirma com veemência que uma atividade de leitura será bem mais motivadora quando o conteúdo for de interesse do leitor aliada a um objetivo.

Ainda que seja mais desafiante para o docente, em uma turma de crianças com histórias de vida e desejos diversos, atender ao interesse de todas, a motivação pode ser despertada de acordo com seu entusiasmo ao apresentar uma proposta de leitura, ao fazer opções de modo criterioso. Portanto, a escolha das leituras de forma intencional e direcionada aos alunos é essencial na ação de professores que objetivam a formação de leitores.

As pesquisadoras Gouveia e Leal (2001 apud LEAL; ALBUQUERQUE, 2010) acrescentam que o contexto motivador que contribui para a aprendizagem da leitura e da escrita das crianças vai além de materiais e livros adequados, passa pela convivência com adultos leitores e escritores que possuem importante representação em sua vida, como pais e professores.

Ao incentivar a leitura para as crianças, contudo, é necessário que docentes planejem a ação, respeitando critérios para a escolha dos materiais, Revista Educação Online, Rio de Janeiro, n. 37, mai-ago 2021, p. 55-72 
antecipem possíveis dificuldades que as crianças podem apresentar, evitem situações de concorrência e promovam situações de uso real da leitura, como também respeitem 0 ritmo das crianças ao elaborarem suas próprias interpretações.

\section{Nas trilhas da investigação}

Os recortes das pesquisas que compuseram este texto envolveram estudos de campo e adotaram a abordagem qualitativa do tipo descritiva. Como pontua Lakatos e Marconi (2009, p. 272), "[...] a finalidade da pesquisa científica não é apenas a de fazer um relatório ou descrição dos dados pesquisados empiricamente, mas relatar o desenvolvimento de um caráter interpretativo no que se refere aos dados obtidos." Assim, a intenção desse texto é apresentar nossas interpretações acerca dos fenômenos pesquisados.

Minayo (2015, p. 14), pesquisadora que considera metodologia como "[...] o caminho do pensamento e a prática exercida na abordagem da realidade", argumenta que a pesquisa de campo proporciona aproximação do pesquisador na realidade sobre a problemática do assunto em questão, sendo possível estabelecer interações com o objeto do estudo e construir empiricamente o conhecimento (MINAYO, 2009).

Nos estudos de campo, optamos pela observação e pela entrevista ${ }^{3}$ semiestruturada como técnicas investigativas. Como delimitação deste artigo, apresentamos, como mencionado na introdução, apenas uma das categorias extraídas das entrevistas realizadas, aquela que encontrou, na confluência das duas pesquisas, um ponto em comum.

As observações nos proporcionaram confrontar o que vimos nas interações entre professoras e crianças em sala com o que ouvimos nas interlocuções com as docentes, materializando a triangulação com o objetivo de enriquecer as análises.

Conforme Triviños (1987, p. 146), a entrevista semiestruturada, "[...] ao mesmo tempo em que valoriza a presença do investigador, oferece todas as

\footnotetext{
${ }^{3}$ Com o Termo de Consentimento Livre e Esclarecido (TCLE) lido e assinado por todas as docentes entrevistadas, bem como o parecer do Comitê de Ética.
}

Revista Educação Online, Rio de Janeiro, n. 37, mai-ago 2021, p. 55-72 
perspectivas possíveis para que o informante alcance a liberdade e a espontaneidade necessárias, enriquecendo a investigação."

Partindo desse entendimento, utilizamos roteiros previamente elaborados, compostos de questões abertas, com o intuito de captar nas respostas a expressão dos sujeitos, para orientar nossas análises sobre a problemática investigada.

As falas foram registradas em gravador de voz e, posteriormente, transcritas e retextualizadas (MARCUSCHI, 2010), objetivando maior clareza e adequação à redação dos textos, mantendo a essência das expressões. Para tratar os dados construídos, utilizamos a Análise de Conteúdo (AC) (BARDIN, 2011), complementada com a triangulação (MINAYO; ASSIS; SOUZA, 2005) dos dados obtidos por meio das técnicas empreendidas.

Com a AC, buscamos as unidades de sentido, a fim de realizar a categorização. Conforme Bardin (2011), a AC corresponde à superação da incerteza e o enriquecimento da leitura, sendo possível aplicar a todas as formas de comunicação, com base no código linguístico, independente do suporte.

Portanto, qualquer comunicação entre o emissor e o receptor em qualquer veículo de significados pode ser interpretada pelas técnicas dessa metodologia de análise. Segundo a referida autora, a AC é definida como

[...] conjunto de técnicas de análise das comunicações, visando a obter, por procedimentos sistemáticos e objetivos de descrição do conteúdo das mensagens, indicadores (quantitativos ou não), que permitem a inferência de conhecimentos relativos às condições de produção/recepção (variáveis inferidas) dessas mensagens. (BARDIN, 2011, p. 48)

Desse modo, para analisar os dados coletados e classificá-los em categorias, investigamos 0 que as mensagens tinham em comum para proceder ao agrupamento. De acordo com a metodologia expressa por Bardin (2011), a categorização segue uma estrutura dividida em duas etapas: o inventário, em que são isolados os elementos; e a classificação, em que os elementos seguem certa organização. Portanto, as falas dos sujeitos constituíram textos analisados minunciosamente, a fim de identificar as categorias. 
Já com a triangulação dos dados construídos a partir das entrevistas e das observações, foi possível perceber pontos de interseção entre o falado e o realizado. Na estratégia da triangulação, "técnicas qualitativas são utilizadas e combinadas, visando a produzir um conhecimento mais aprofundado da realidade" (MINAYO; ASSIS; SOUZA, 2005, p. 91). Nesse sentido, intencionamos encontrar semelhanças e/ou diferenças entre os discursos das docentes e aquilo efetivamente realizado em suas ações didáticas.

A triangulação a que nos propusemos significa, para Minayo, Assis e Souza (2005), uma combinação de diversos e múltiplos pontos de vista que se cruzam, a fim de reunir o máximo de informações; consiste na "[...] visão de vários informantes e o emprego de uma variedade de técnicas de coleta de dados que acompanha o trabalho de investigação" (MINAYO; ASSIS; SOUZA, 2005, p. 29).

Assim, os dados construídos por meio das técnicas escolhidas foram cruzados após terem sido pré-analisados. Desse modo, o significativo material e os meios para obter as informações, quando cruzados, convergiram para decifrar o objeto da investigação de forma mais profunda.

As oito professoras, sujeitos da análise, foram, neste texto, identificadas por nomes femininos, todos formados por cinco letras, seguindo a ordem alfabética. As professoras e suas respectivas turmas são: Alice e Bruna, do Infantil V; Clara e Diana, do $1^{\circ}$ ano; Elisa e Fábia, do 2ํan ano; Greta e Hilda do $3^{\circ}$ ano. A opção por identificar as docentes com nomes fictícios se justifica pela garantia do anonimato dos sujeitos do estudo, conforme preceitos éticos da pesquisa científica.

Para atender a esses preceitos, baseamo-nos na Resolução no 466, de 12 de dezembro de 2012, do Conselho Nacional de Saúde (CNS). Essa resolução preceitua que "as pesquisas envolvendo seres humanos devem atender aos fundamentos éticos e científicos pertinentes" (CONSELHO NACIONAL DE SAÚDE, 2013, p. 60). Desse modo, em seu item III - Dos aspectos éticos da pesquisa envolvendo seres humanos, alínea i, recomendanos a

prever procedimentos que assegurem a confidencialidade e a privacidade, a proteção da imagem e a não estigmatização dos participantes da pesquisa, 
garantindo a não utilização das informações em prejuízo das pessoas e/ou das comunidades. (CONSELHO NACIONAL DE SAÚDE, 2013, p. 60)

$\mathrm{Na}$ seção a seguir, analisamos e discutimos a categoria selecionada para este artigo, baseando-nos em estudos teóricos, que fundamentaram a temática e a prática docente envolvida no ensino e na aprendizagem da leitura.

\section{Nas tramas das ações docentes}

As perguntas dos roteiros de entrevista buscaram investigar junto às professoras o que elas consideravam para escolher os livros que seriam trabalhados nas atividades de leitura, assim como a forma como selecionavam as leituras que propunham às crianças no cotidiano das interações.

Das respostas surgiram elementos como: o interesse dos alunos, a necessidade de contemplar a realidade e a aproximação ao cotidiano deles, sem, no entanto, deixar de buscar a diversidade de gêneros, e a adequação ao nível de compreensão.

A temática dos projetos didáticos da escola foi ponto em comum nas respostas de algumas professoras. Uma das escolas pesquisadas desenvolvia mensalmente projetos de trabalho, em que todas as turmas participavam; desse modo, as professoras, no planejamento, levavam em conta a inserção do assunto central dos projetos.

A professora Alice, docente do Infantil $V$, revelou que seguia 0 norteamento do livro didático utilizado, as orientações da coordenadora pedagógica, bem como de pesquisas e formações continuadas de que participava. Enfatizou a troca de ideias como ponto relevante nessa escolha, em especial com a professora do $1^{\circ}$ ano, como se pode ver no trecho a seguir:

Às vezes eu peço orientação [...] também da Clara que está no primeiro ano, a gente pega muitas ideias uma da outra para trabalhar, porque são séries muito parecidas e, às vezes, o que ela trabalha eu acho interessante [...] e trabalho também. Já que a gente está quase sempre juntas no planejamento [...]. (PROFESSORA ALICE, Infantil V)

Durante as observações, percebemos a concretude da fala de Alice na sua ação didática, pois a docente propôs atividades bem parecidas com as da colega Clara, professora do $1^{\circ}$ ano, ajustando, entretanto, o nível de abordagem a sua turma. Esse fato foi corroborado por Clara também em sua 
entrevista, em que mencionou a parceria entre as duas na elaboração do planejamento semanal.

A professora do Infantil V, Bruna, mencionou os gêneros textuais, em especial, os literários, por considerar serem mais adequados ao trabalho de leitura com crianças pequenas. No excerto a seguir, exemplifica sua ação: "esse mês eu trabalhei fábulas, é sobre o respeito que a gente estava trabalhando, trabalhei $A$ formiga e a pomba, O cão e o leão, uma coisa assim. Trabalhei umas duas fábulas [...] sempre dando exemplos, dando mensagens (PROFESSORA BRUNA, Infantil V).

Além do exposto, Bruna (Infantil V) se aproximou de Clara ( $1^{\circ}$ ano), ao citar em sua resposta o Cantinho da Leitura ${ }^{4}$ como uma opção para sua escolha. Nessa direção, os livros na sala de aula, espaço de interação cotidiana de crianças e professora, despertavam o interesse, constituindo um acervo disponível ao manuseio e apreciação.

Teberosky e Colomer (2003, p. 145) ressaltam a importância dessa organização, ao afirmarem que "Prover o espaço das crianças com histórias, poemas ou livros informativos é uma condição essencial para favorecer o acesso à língua escrita e para motivar o desejo de aprender a ler [...]".

A professora Clara indicou como os projetos da escola orientavam as escolhas de suas propostas à turma e como essa ação podia formar as preferências e motivar os alunos a ler. A docente assim expressou:

[...] no projeto Folclore, que aconteceu em agosto, eu fui à biblioteca da escola, dei uma pesquisada, peguei uns livros, levei pra sala e, até hoje, eles gostam muito daquele livro Bumba-boi, então, vai ficar sempre lá. Quando eu percebo que eles gostam de um texto, de um livro, eu deixo lá pra que eles possam sempre estar olhando, sempre estar em contato com o livro. (PROFESSORA CLARA, $1^{\circ}$ ano)

De fato, em uma das aulas observadas, Clara realizou para a turma a leitura de uma história. Ela iniciou dizendo que, ao ver aquela história, havia lembrado das crianças, pois sabia que eles gostariam. Tratava-se da história

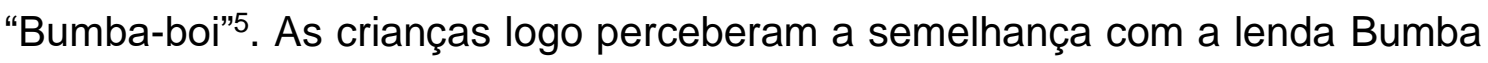

\footnotetext{
${ }^{4}$ Espaço na sala de aula destinado aos livros literários.

5 Livro de Fabiana Ferreira Lopes (2011), do acervo da escola, fornecido pelo Programa Nacional do Livro Didático (PNLD), obras complementares 2013/2014/2015, para uso das turmas de $2^{\circ}$ ano.
}

Revista Educação Online, Rio de Janeiro, n. 37, mai-ago 2021, p. 55-72 
meu boi já lida e comentada durante o projeto em curso, bem como a sutil diferença no título. A professora questionou aos alunos sobre o que sabiam sobre tal lenda, promoveu a leitura da imagem da capa do livro e do nome da autora.

As crianças lembraram que uma delas havia contado a lenda para os demais, inclusive de outras turmas, com riqueza de detalhes, e solicitaram à amiga que o fizesse novamente, o que foi prontamente atendido pela criança e incentivado pela professora.

Na sequência, a docente propôs atividades de leitura e composição da palavra bumba meu boi. Enquanto realizavam a atividade, as crianças comentavam entre si sobre a lenda e se puseram a cantar a música que apresentariam na culminância do projeto.

Sobre as razões da escolha das leituras para a turma, a professora Diana, docente do $1^{\circ}$ ano, ressaltou:

Em primeiro lugar, que cause nele interesse, que ele goste; e, em segundo, que ele goste da ideia e tenha interesse de ler. Primeiro, causar esse impacto nele do atrair, atração. Acho que é o principal para as crianças dessa série e dessa idade: causar atração para leitura, desejo. (PROFESSORA DIANA, $1^{\circ}$ ano)

A fala da professora Diana retrata sua prática, pois, em um dos momentos observados, permitiu que as crianças escolhessem os livros para a leitura deleite ${ }^{6}$, momento dedicado à fruição e ao encantamento das crianças por meio da leitura da professora e, em seguida, realizou a leitura do livro gigante dos Três Porquinhos ${ }^{7}$, um dos escolhidos pelas crianças.

Souza e Leal (2012, p. 10) ressaltam que situações em que pessoas leem para as crianças são importantes e contribuem para o desenvolvimento de diferentes capacidades, dentre elas, a de "[...] compreender textos lidos por

\footnotetext{
${ }^{6}$ Essa estratégia didática foi tema de um artigo de nossa autoria, cuja referência consta a seguir:

SOARES, Silvana Mendes Sabino; SILVA, Olívia Coelho da; RIBEIRO, Ana Paula de Medeiros. Leitura deleite: o encantamento na formação de professores alfabetizadores. In: SEMINÁRIO ESTADUAL DE PRÁTICAS EDUCATIVAS, MEMÓRIAS E ORALIDADES, 4., 2017, Fortaleza. Anais eletrônicos [...]. Fortaleza: UECE, 2017. p. 1146-1152. Disponível em: <https://8b176672-f618-4c17-a0e0-

3ebdcfe16e53.filesusr.com/ugd/65f02d_e1571da6ca11491193d93708646421b8.pdf>. Acesso em: 13 abr. 2020..

${ }^{7}$ Livro literário constituinte do acervo da sala de aula.
}

Revista Educação Online, Rio de Janeiro, n. 37, mai-ago 2021, p. 55-72 
outras pessoas, de diferentes gêneros e com diferentes propósitos [...]." Dessa forma, a professora Diana atendeu ao interesse de alguns alunos, contemplando um dos objetivos da leitura: ler por prazer.

Isabel Solé (1998, p. 91) considera que "[...] as situações de leitura mais motivadoras também são as mais reais: isto é, aquelas em que a criança lê para se libertar, para sentir o prazer de ler [...]". Ao atender a esse objetivo, a professora Diana estimulou as crianças a realizarem escolhas de acordo com suas preferências e, assim, pôde perceber seus interesses de leitura e planejar momentos significativos e prazerosos.

A professora Elisa, docente do $2^{\circ}$ ano, nos possibilitou apreciar em sua fala, que a prática seguia um planejamento quanto ao tipo de textos que utilizava, e que esses deveriam ter uma articulação com os conteúdos que seriam contemplados. Foi possível perceber que ela utilizava diversos materiais para enriquecer a aula.

Seu discurso foi relacionado à prática em vários momentos da observação. Percebemos o uso de materiais diversificados que não havia no livro didático; um exemplo disso foi um folheto de propaganda de remédio, em que a professora contemplou o gênero textual em articulação com a disciplina de ciências. No excerto a seguir, Elisa explicita sua intenção:

O objetivo com relação aos textos que eu escolho é a questão de abordar o gênero que eu quero trabalhar com eles, para que eles possam consolidar a estrutura, além da compreensão do gênero. Com relação ao livro, geralmente, eu tento escolher, abordando temas que eu vou trabalhar nos conteúdos do cotidiano. Então, a gente utiliza muito as obras complementares do PNLD, porque no próprio manual já vem especificando coisas que você pode trabalhar a partir da leitura e é só complementar. (PROFESSORA ELISA, $2^{\circ}$ ano)

Fábia, professora do $2^{\circ}$ ano, se mostrou preocupada com a compreensão dos alunos e relatou, no trecho que segue, a forma como age em relação a essa preocupação:

Eu procuro ver o nível de compreensão deles, que seja do nível de aprendizagem, porque eu não posso escolher um livro que eles não vão entender a leitura, com palavras mais difíceis. Eu procuro textos que sejam de acordo com a realidade deles, com a idade, da maturidade deles. (PROFESSORA FÁBIA, $2^{\circ}$ ano) 
A professora Fábia demonstrou atenção ao vocabulário utilizado nos textos e, por isso, buscava oferecer leituras adequadas à idade das crianças. Em suas aulas, foi observado que realizou a mediação das atividades de leitura propostas no material didático disponibilizado, que apresentava variados gêneros textuais. Durante as aulas de leitura, a professora normalmente procurava ativar os conhecimentos prévios das crianças antes de adentrar à nova leitura.

A professora do $3^{\circ}$ ano, Greta, ao falar sobre o prazer pela leitura, nos levou a relembrar o dia observado, em que promoveu, na aula, a leitura do romance $O$ jardim secreto 8 .

A leitura da professora foi muito expressiva. Ela se utilizou de diferentes vozes para diferenciar os personagens e transmitir as emoções de cada um por meio do tom. Foi perceptível que sua leitura despertou nas crianças prazer em ser ouvida e causou desejo de saber mais sobre a história. Sua ação vai ao encontro das ideias de Maciel (2010), que assevera:

Além de decidir sobre o que ler e para quê, o professor também imprime maior qualidade a seu trabalho quando se dedica a pensar em como ler para seus alunos ou com eles. Afinal, sabe-se que as primeiras experiências de leitura da criança são marcantes não só pela compreensão dos significados do texto, mas também pelos modos de ler, pela entonação de voz do leitor, pela relação afetiva com o leitor-mediador e com o ambiente em que a leitura se desenvolve, por tudo aquilo que circunda o texto e com ele estabelece relações [...]. (MACIEL, 2010, p. 33-34, grifos da autora)

No caso do livro trabalhado pela professora Greta, por se tratar de um texto longo, foi lido em capítulos, provocando a curiosidade dos alunos. Conforme Paiva, Paulino e Passos (2006, p. 25), "A leitura literária é associada à reflexão e à imaginação, quando estimula nossa percepção a romper com o automatismo da rotina cotidiana. Essa característica faz parte da função social da literatura."

Desse modo, inferimos que a referida professora proporcionou em sua leitura o tratamento adequado ao gênero textual escolhido, pois "Ao entrar em contato com novas 'realidades', o leitor adquire novas experiências, podendo refletir sobre sua vida, perceber sua própria realidade de outra maneira."

${ }^{8}$ Romance constituinte do acervo da professora, escrito por Frances Hodgson Burnett e adaptado por Ana Maria Machado.

Revista Educação Online, Rio de Janeiro, n. 37, mai-ago 2021, p. 55-72 
(PAIVA; PAULINO; PASSOS, 2006, p. 25, grifo das autoras). Em sua fala, Greta ressaltou:

Levando em conta o texto da forma mais diversificada possível, para que ele possa entender qual o tipo de gênero textual e que a gente possa ter conhecimento para vivência dele lá fora. Para que ele possa diferenciar uma receita, um texto instrucional, o que é um conto, um poema, ou seja, quando ele se deparar com várias situações dessas, um anúncio de jornal, ele saiba distinguir o que é cada um e qual a função de cada um. E quando eu escolho os livros, o objetivo em si é mais a questão prazerosa, pela leitura mesmo [...] quando eu estou contando as histórias, eu tento colocar a leitura de uma forma viva, para quando ele for ler, ele tente dentro dele, trazer essa história viva, dentro da imaginação. Quando ele estiver lendo, mesmo que seja silenciosamente, ele consiga trazer essa história viva dentro dele. Ele consiga não só na imaginação, mas ele consiga, talvez, até no real, ver essa história. (PROFESSORA GRETA, $3^{\circ}$ ano)

A prática da professora Greta encontra fundamento nas recomendações de Paiva, Paulino e Passos (2006), ao se referirem a ações que levam em conta a utilização de textos literários, conforme mencionam no trecho a seguir:

Diante de um texto literário, que é uma produção artística, espera-se que o leitor se sinta em interação com uma obra de arte. Essa interação lhe permite uma vivência que inclui, além de seu interesse intelectual, seu lado emocional: sua imaginação, desejos, medos, admirações. (PAIVA; PAULINO; PASSOS, 2006, p. 21)

Em relação à fala da professora Hilda, do $3^{\circ}$ ano, emergiu a preocupação em partilhar com os alunos a diversidade de gêneros textuais que existe na sociedade. Foi possível perceber, nas aulas observadas, que articulava muito bem suas ações com o livro didático, uma vez que preparou os alunos para utilizar as atividades propostas pelo livro: “[...] A minha preocupação é ter textos variados. Os livros deles trazem muito. A gente trabalha receita, conto, textos informativos" (PROFESSORA HILDA, $3^{\circ}$ ano).

Maciel (2010, p. 15), em um artigo que compartilha uma pesquisa realizada por Telma Ferraz Leal e Eliana Borges Correia de Albuquerque, com entrevistas com crianças e jovens sobre suas experiências de leitura, ressalta que as autoras intencionaram compreender os motivos que levam uma criança ou um jovem a gostar de ler.

$\mathrm{Na}$ referida pesquisa, verificaram que "[...] a atração pela leitura está diretamente ligada às descobertas do corpo, da vida, sem que se descarte as inclinações para o sonho e para a fantasia". E para que a motivação continue, 
as pesquisadoras aconselham que se ofereça aos alunos leituras diversificadas, "[...] sem jamais desqualificar o aluno pelo gosto manifestado por este ou aquele gênero" (MACIEL, 2010, p. 15).

Dentre os gêneros textuais mais citados pelas docentes, destacaram-se as histórias infantis, entendidas aqui como os contos clássicos e contemporâneos; entretanto, foram mencionados, também, lendas, fábulas, poemas, receitas, parlendas, placas de trânsito, listas e cantigas de roda.

O trabalho sistemático com gêneros textuais com crianças em fase de alfabetização e desenvolvimento da competência leitora, numa evolução de complexidade por ano de escolaridade, contribui sobremaneira para a formação de leitores, com amplo repertório linguístico e, consequentemente, para a autonomia em sociedade, nas situações reais de uso dos textos.

Nessa direção, os pesquisadores Schneuwly e Dolz (2004, p. 64, grifo dos autores) afirmam: "Do ponto de vista do uso e da aprendizagem, o gênero pode, assim ser considerado um megaisntrumento que fornece um suporte para a atividade, nas situações de comunicação, e uma referência para os aprendizes".

Os gêneros citados pelas docentes nas entrevistas e mediados em sala com as crianças encontram amparo na teoria que fundamenta as ações pedagógicas com a língua materna. $O$ trabalho com os gêneros textuais é, por esse motivo, um importante elemento na formação de leitores autônomos e competentes para lidar com a língua além dos muros das escolas.

Dessa forma, o convívio com a diversidade textual aproxima o conteúdo escolar da vida cotidiana das crianças, que vislumbram a possibilidade de, na escola, aprenderem aquilo que vivenciam fora dela. Para Teberosky e Colomer (2003, p. 85), selecionar textos diferentes

responde ao objetivo de favorecer a permeabilidade entre o ambiente social e a escola [...] deixar entrar os escritos não (tradicionalmente) escolares facilita não apenas a contextualização da aprendizagem, mas favorece um movimento inverso: a participação infantil, fora da escola, no mundo da escrita. (TEBEROSKY; COLOMER, 2003, p. 85)

Essas ações põem as crianças em contato com a língua escrita e possibilitam a apropriação de conhecimentos acerca do sistema alfabético, bem como da funcionalidade dos textos que circulam socialmente, constituindo- 
se em uma forma de inserção consciente na cultura letrada com que já convivem.

\section{Nas perspectivas da chegada}

Neste artigo, descrevemos um recorte de pesquisas em que investigamos o que professoras alfabetizadoras consideravam para escolher os livros que seriam trabalhados nas atividades de leitura com crianças, assim como a forma de selecionarem as leituras que propunham no cotidiano das interações.

Os achados mostraram que as professoras consideravam o interesse, a necessidade de contemplar a realidade e a aproximação ao cotidiano sem, no entanto, deixar de buscar a diversidade de gêneros, a adequação ao nível de compreensão das crianças e o currículo escolar.

A pesquisa revelou que as professoras escolhiam as leituras de acordo com 0 interesse dos alunos, percebido nos momentos em que era disponibilizado o acervo presente na sala de aula e em situações de pesquisa de novas leituras, quando desejavam trabalhar a partir de situações que emergiam no cotidiano da sala de aula. Elas revelaram aliar o prazer da leitura aos conteúdos que precisavam contemplar na rotina escolar.

Ademais, as professoras demonstraram em sua prática compreender a importância de mediar o acesso dos alunos aos mais variados gêneros textuais que circulam na sociedade, respeitando a maneira como cada um merece ser tratado no ambiente escolar, para motivar o desejo dos alunos pela leitura e contribuir para sua autonomia, nas situações reais de uso da língua, nas práticas sociais.

\section{Referências bibliográficas}

AUSUBEL, David P.; NOVACK, Joseph D.; HANESIAN, Helen. Psicologia da educação. Rio de Janeiro: Ed. Internacional, 1980.

BARDIN, Laurence. Análise de conteúdo. São Paulo: Edições 70, 2011. 
BRASIL. CONSELHO NACIONAL DE SAÚDE. Resolução no 466, de 12 de dezembro de 2012. In: Diário Oficial da União, Brasília, DF, n. 112, seção 1 , p. 59, 13 jun. 2013. Disponível em:

<http://pesquisa.in.gov.br/imprensa/jsp/visualiza/index.jsp?data=13/06/2013\&jor nal=1\&pagina=59\&totalArquivos=140 . Acesso em: 12 abr. 2020.

$\mathrm{KOCH}$, Ingedore Villaça; ELIAS, Vanda Maria. Ler e compreender: os sentidos do texto. 3. ed. São Paulo: Contexto, 2013.

LAKATOS, Eva Maria; MARCONI, Marina de Andrade. Metodologia científica. 2. ed. São Paulo: Atlas, 2009.

LEAL, Telma Ferraz; ALBUQUERQUE, Eliana Borges Correia de. Leitura e formação de leitores na escola. In: PAIVA, Aparecida; MACIEL, Francisca; COSSON, Rildo (Coords.). Leitura: volume 20: ensino fundamental. Brasília, DF: MEC, 2010. p. 89-106. Disponível em:

$<$ http://educacaointegral.mec.gov.br/images/pdf/bibioteca/2011_literatura_infant il_capa.pdf>. Acesso em: 12 abr. 2020.

MACIEL, Francisca Isabel Pereira. Educação, leitura e literatura: diálogos possíveis. In: PAIVA, Aparecida; MACIEL, Francisca; COSSON, Rildo

(Coords.). Leitura: volume 20: ensino fundamental. Brasília, DF: MEC, 2010. p. 9-22. Disponível em:

$<$ http://educacaointegral.mec.gov.br/images/pdf/bibioteca/2011_literatura_infant il_capa.pdf>. Acesso em: 12 abr. 2020.

MARCUSCHI, Luiz Antônio. Da fala para a escrita: atividades de retextualização. 10 ed. São Paulo: Cortez, 2010.

MARCUSCHI, Luiz Antônio. Produção textual, análise de gêneros e compreensão. São Paulo: Parábola Editorial, 2008.

MINAYO, Maria Cecília de Souza (Org.). Pesquisa social: teoria, método e criatividade. 34 ed. Petrópolis: Vozes, 2015.

MINAYO, Maria Cecília de Souza (Org.). Pesquisa social: teoria, método e criatividade. Petrópolis: Vozes, 2009.

MINAYO, Maria Cecília de Souza; ASSIS, Simone Gonçalves de; SOUZA, Edinilsa Ramos de (Orgs.). Avaliação por triangulação de métodos: abordagem de programas sociais. Rio de Janeiro: Editora Fiocruz, 2005.

PAIVA, Aparecida; PAULINO, Graça; PASSOS, Marta. Literatura e leitura literária na formação escolar: caderno do professor. Belo Horizonte: Ceale, 2006.

SCHNEUWLY, Bernard; DOLZ, Joaquim. Gêneros orais e escritos na escola. Campinas: Mercado das letras, 2004.

SOARES, Magda. Letramento: um tema em três gêneros. Belo Horizonte: Autêntica, 1998.

SOLÉ, Isabel. Estratégias de leitura. 6 ed. Porto Alegre: ArtMed, 1998.

SOUZA, Ivane Pedrosa de; LEAL, Telma Ferraz. Os diferentes textos a serviço da perspectiva do alfabetizar letrando. In: BRASIL. Ministério da Educação.

Pacto Nacional pela Alfabetização na Idade Certa: os diferentes textos em

Revista Educação Online, Rio de Janeiro, n. 37, mai-ago 2021, p. 55-72 
salas de alfabetização: unidade 4 | ano 1. Brasília, DF: MEC, 2012. p. 6-14. Disponível em:

<https://www.pomerode.sc.gov.br/downloads/Arquivos/SED/ano1/unidade_05 ano_01_azul.pdf>. Acesso em: 14 abr. 2020.

TEBEROSKY, Ana; COLOMER, Teresa. Aprender a ler e escrever: uma proposta construtivista. Porto Alegre: ArtMed, 2003.

TRIVIÑOS, Augusto Nibaldo Silva. Introdução à pesquisa em ciências sociais: a pesquisa qualitativa em educação. São Paulo: Atlas, 1987. 